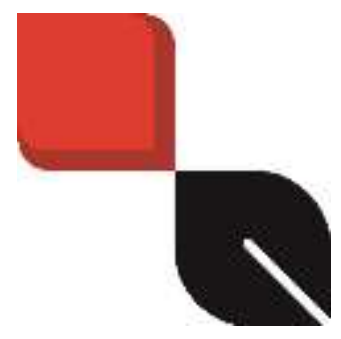

Cuadernos del CILHA n 34 - 2021 | publicación continua

ISSN 1515-6125 | EISSN 1852-9615

http://revistas.uncu.edu.ar/ojs/index.php/cilha/

CC BY-NC 2.5 AR

Recibido: 10/05/2021 Aprobado: 11/06/2021

PP. 1-21

DOI: https://doi.org/10.48162/rev.34.001

\title{
El país de la selva: la bruja y el gótico mesopotámico en "Tela de araña" de Mariana Enríquez
}

The land of the jungle: the witch and the mesopotamian gothic in Mariana Enríquez's "Tela de araña"

Marcos Seifert

Universidad Nacional de Hurlingham Consejo Nacional de Investigaciones Científicas y Técnicas de Argentina

marcseifert19@gmail.com

Argentina

Resumen: El relato "Tela de araña" de Mariana Enríquez incluido en Las cosas que perdimos en el fuego (2016) puede pensarse como una manifestación del "gótico mesopotámico" en la medida en que funciona como reescritura y desvío del trabajo con la selva y el espacio que se encuentra en la narrativa de Horacio Quiroga. El propósito de este texto es explorar no sólo las características que de este regionalismo gótico, sino también la relevancia de la figura de la bruja o hechicera en la que se intersectan y superponen los sentidos vinculados con las leyendas y creencias locales y los rasgos ligados a motivos o modelos que trascienden los límites de lo nacional y lo regional. En "Tela de araña", tanto el ambiente hostil de la selva, como los relatos de aparecidos y el personaje de la bruja adquieren un sentido político antiestatal y antipatriarcal. El cruce entre lo local y lo global debe leerse aquí iluminado por el concepto de globalgothic 
(Botting y Edwards, 2015) dado que la búsqueda de la resonancia genérica que surge de las leyendas y relatos populares funcionan como la expresión específica y local de los tropos y estrategias literarias que la crítica literaria ha asociado históricamente con el gótico.

Palabras clave: Regionalismo gótico, Horacio Quiroga, Relatos de fantasmas, Brujería.

Abstract: Mariana Enríquez's short story "Tela de araña" included in Las cosas que perdimos en el fuego (2016) can be thought as a manifestation of "mesopotamian gothic" because it functions as a rewriting of the jungle found in Horacio Quiroga's narrative. The purpose of this text is to explore not only the characteristics of this Gothic regionalism, but also the relevance of the figure of the witch or sorceress. The aspects of this figure are linked to the local legends and beliefs and also to motives or models that transcend national and regional boundaries. In "Tela de araña ", both the hostile environment of the jungle, as the stories of the apparitions with the figure of the witch acquire an antistate and anti-patriarchal political sense. The crossroads between the local and the global must be read here enlightened by the concept of globalgothic (Byron, 2015) where the legends and popular stories functions as a specific and local expression of tropes and strategies that literary criticism has historically associated with gothic.

Kewords: Gothic regionalism, Horacio Quiroga, Ghost stories, Witchcraft.

Dos compilaciones de estudios críticos como Tropical Gothic in Literature and Culture: The Americas (2016) y Latin American Gothic in Literature and Culture (2017) junto con el libro Selva de fantasmas (2017) de Gabriel Eljaiek-Rodríguez son algunos ejemplos de un creciente interés en pensar los transplantes y adaptaciones del género gótico en América Latina. El objetivo de estos trabajos ha sido comprender la adaptación del género a una nueva geografía como un capítulo más de los procesos de transculturación y tropicalización. Particularmente, Sandra Casanova-Vizcaíno e Inés Ordiz en la introducción de su volumen de 2017 hacen hincapié en la pertinencia de entender este fenómeno como una manifestación más de lo que Glennis Byron Ilama Globalgothic. Este concepto alumbra el modo en que el género se ha vuelto un lenguaje para expresar nuevos terrores a escala mundial; miedos que toman la forma de antiguos tropos góticos como vampiros, fantasmas, brujas y zombies. El término propuesto por Byron permite comprender textualidades que presentan un carácter tanto local como global. Así como la globalización facilita los intercambios culturales que dan lugar a nuevas

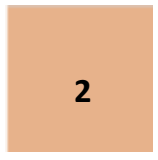

Cuadernos del CILHA n $34-2021$

ISSN 1515-6125 | EISSN 1852-9615

CC BY-NC 2.5 AR

http://revistas.uncu.edu.ar/ojs/index.php/cilha/ 
formas del gótico, los tropos de la tradición gótica son reformulados para dar cuenta de ansiedades, nuevos miedos y efectos de un mundo globalizado $(2015$, p.2)

Muchos años antes de la proliferación de estas lecturas y abordajes, Ricardo Piglia en un artículo titulado "Quiroga y el horror" cita al crítico norteamericano Leslie Fiedler:

En Europa la novela gótica es contemporánea de la ascensión de la burguesía y sus personajes huyen de los símbolos del orden feudal perfectamente resumidos en la imagen del castillo en ruinas. Ahora bien, ese esquema en América no pudo ser traspuesto del mismo modo pues acá evidentemente no hay castillo en ruinas. Lo único antiguo en el nuevo mundo es la selva, los templos y las terrazas agrícolas (Piglia, 1993: p. 64).

En su libro Love and Death in the American Novel (1960), Fiedler esboza esta idea y reflexiona sobre el cambio de significado que implica este trueque geográfico o paisajístico que pasa a ubicar el mal no en los monumentos decadentes de una clase social agonizante, sino en la naturaleza indomable. Fiedler lleva esta distinción a la tópica freudiana y sostiene que mientras el gótico europeo identifica la oscuridad con el super-ego (con implicaciones revolucionarias), el gótico americano sitúa la maldad en el ello (las derivaciones de esto serían conservadoras, agrega) (1997, p.148). Propongo pensar el gótico regional que postula Enríquez en "Tela de Araña" como una forma de subvertir estas implicaciones que realiza Fiedler: situar el mal en las pulsiones y deseos que circulan por fuera de los cauces normativos sugiere una violencia que toma forma desde abajo y arremete contra los sistemas de opresión sociales y estatales que permean la vida cotidiana.

El cuento "Tela de araña" de Mariana Enríquez, publicado como parte del libro Las cosas que perdimos en el fuego (2016), puede leerse como un prisma que refracta muchas de las cuestiones centrales que se destacan en los estudios sobre el gótico latinoamericano: el trabajo con el ambiente, el relato enmarcado de historias de aparecidos, la imbricación entre geografía y oscuridad, el cruce entre lo global y lo local. En una entrevista en la que se la interroga sobre la influencia de Horacio Quiroga en su escritura, Enríquez puntualiza que lo que gravita sobre algunas de sus narraciones es "el ambiente opresivo de la selva misionera". La autora etiqueta su narración "Tela de 
araña" como un relato "gótico mesopotámico" en el que se juega "una apropiación oblicua y contemporánea" de Horacio Quiroga ${ }^{1}$. El propósito de este texto es explorar no solamente las particularidades que adquiere este regionalismo gótico propuesto por la autora, sino también la de la construcción de la figura de la bruja o hechicera en la que se intersectan y superponen los sentidos locales y los rasgos universales.

Para entender esta renovación del gótico para Enríquez no debe dejarse de lado el lazo que establece esta tradición con la poética y los códigos del realismo. La definición de un espacio ficcional que es simultáneamente gótico y realista parece difícil de calibrar debido a la tendencia a considerar la tradición gótica como una formulación exclusivamente arraigada en formas literarias no miméticas. Sin embargo, es importante entender esta articulación en línea con lo que explica Sandra Contreras (2013) cuando refiere lo que extrae César Aira de la lectura lukácsiana de Balzac: la idea del "gran realista" como aquel que sintoniza "las fuerzas latentes de una sociedad" (p. 7) y las expresa a través de una forma que crea sus propios paradigmas. El realismo gótico de Enríquez es una invención en la que las formas y figuras reconocidas y reconocibles de la tradición cultural del terror portan una carga socio-política que constituye una intervención en los antagonismos sociales e ideológicos que atraviesan sus relatos. El gótico intercede en el dialogismo que permea las narraciones, ya que está inevitablemente impregnado de un componente social, de un posicionamiento político y una visión del mundo. En "Tela de araña" el gótico mesopotámico (el ambiente hostil de la selva junto con los relatos de aparecidos que ahí circulan) y la figura de la bruja adquieren un claro sentido antiestatal y antipatriarcal. Frente al terror de Estado y los abusos patriarcales que se infiltran y se naturalizan en la cotidianeidad emergen los terrores del gótico como máquina de guerra. Este sintagma deleuziano es apropiado para dar cuenta del uso del gótico de Enríquez en este relato en la medida en que este término se contrapone al modo en que funciona la violencia del Estado que actúa, como advierten Deleuze y Guattari, por captura. El gótico en "Tela de araña" es lo contrario a

\footnotetext{
${ }^{1}$ Un eslabón entre Quiroga y Enríquez a la hora de pensar un gótico argentino liberado de las imposiciones de la geografía urbana es el relato largo o nouvelle "El impostor" (1948) de Silvina Ocampo. María Negroni no dudó de calificar como "gótico campero" $(2015$, p.232) a esta narración que se desarrolla en un casco de estancia abandonado y que produce mediante un juego de especularidades y confusiones entre el sueño y la realidad un cuestionamiento de la identidad familiar y social.
}

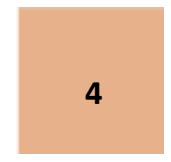

Cuadernos del CILHA n $34-2021$

ISSN 1515-6125 | EISSN 1852-9615

CC BY-NC 2.5 AR

http://revistas.uncu.edu.ar/ojs/index.php/cilha/ 
un aparato de Estado, es el ritual oculto, la selva espesa sin límites, la ruptura de los compromisos burgueses,

sería como la multiplicidad pura y sin medida, la manada, irrupción de lo efímero y potencia de la metamorfosis. Deshace del lazo en la misma medida en que traiciona el pacto. Frente a la mesura esgrime un furor, frente a la gravedad una celeridad, frente a lo público un secreto, frente a la soberanía una potencia, frente al aparato una máquina (2002, p.360).

Enríquez reubica el miedo en el lugar del contrapoder, recuperando así la peligrosidad del desplazado, del subalterno, del excluido. De ahí que tanto Inés Ordiz (2019), como Ana Gallego Cuiñas definan la narrativa de Enríquez como "feminismo gótico" ya que en sus relatos "las mujeres y las clases marginales, afantasmadas, devienen peligrosas y portadoras del terror, al ser las más vulnerables y castigadas por el capital” (2020, p.1).

El cruce entre lo local y lo global que se advierte en el terror desplegado en este relato (en la gotificación regional, en el uso del relato de fantasmas e incluso en la figura de la bruja) debe leerse en el marco del concepto globalgothic que propone Glennis Byron (2015) en tanto la búsqueda de la resonancia gótica que surge de las leyendas y relatos populares funcionan como la manifestación específica y local de los tropos y estrategias literarias que la crítica literaria ha asociado históricamente con el gótico. Ese giro hacia lo propio, lo popular y lo local constituye una versión contemporánea del gótico en la que se produce la confluencia de diferentes tradiciones culturales en un espacio globalizado. En "Tela de araña" se verifica aquello que Byron le atribuye al concepto de globalgothic: el movimiento por medio del cual las formas provistas por los mitos y el folklore regional y nacional se reciclan para pensarse en una nueva temporalidad (2015. p.4) a la vez que se vuelven materia prima de un público y una circulación a escala global.

\section{Regionalismo gótico}

Plantear un gótico regional, propone William Hughes, implica el reconocimiento del margen como un espacio cultural con una potencialidad de cuestionamiento de las 
relaciones de poder entre el outsider y el nativo, el civilizado y el "no-civilizado" (2018, p.15). El trabajo con un lugar o región delineada a partir de sus distinciones geográficas y culturales no debe ser ajeno a la comprensión de las interacciones con espacios mayores, es decir, los intercambios a escala nacional, transnacional o global. (Hedrick, 2017). Si bien el regionalismo gótico se caracteriza por presentar una resistencia no sólo al espacio hegemónico de la nación, sino a nociones dominantes vinculadas al Estado, al género y al capitalismo, la relación con lo exterior debe entenderse más allá de la oposición entre un adentro y un afuera, es decir, como un espacio entramado a través del contacto y la transformación por fuerzas culturales, políticas y económicas. El regionalismo gótico funciona como un regionalismo crítico, y esto es visible en "Tela de araña", ya que nos recuerda que las tradiciones de la región están siempre en diálogo con la modernidad (Hedrick, 2017). En el modo en que se plantea este diálogo estriba una de las diferencias entre el trabajo literario de Horacio Quiroga y el Enríquez.

"Tela de araña" se desarrolla entre Argentina y Paraguay durante los años 80 en algún momento entre los primeros años de la vuelta de la democracia argentina, y la persistencia de la dictadura de Alfredo Stroessner en el país vecino. La narradora da cuenta de una postergada visita a sus familiares en Corrientes para presentarles a su esposo Juan Martín. Como relación con él no es buena y la mujer teme que la mirada de sus parientes se vuelva un reproche por haberse casado con alguien que de forma constante desprecia y dirige sus malos tratos hacia ella, hacia la vida en el interior, y también hacia Natalia prima de la protagonista. Los tres viajan juntos a Asunción y a la vuelta en algún punto de Formosa una falla en el auto los obliga a pasar la noche en un hotel. Durante la cena se encuentran con unos camioneros que cuentan historias de aparecidos. Estos relatos están explícitamente teñidos por la historia reciente: la desaparición de personas en el marco del terror de Estado. A la mañana siguiente, Juan Martín ya no está en el hotel. El relato culmina con la naturalización de su desaparición. A pesar del hallazgo de las pertenencias de Juan Martín en el hotel, la narradora finalmente parece convencerse de que su marido ha decidido partir por la noche, misteriosamente, sin dejar ningún tipo de aviso. El cuento es un relato de viaje al interior y dentro del mismo, otro desplazamiento más allá de la frontera para luego quedar a la deriva "en algún punto de Formosa". Ir desde el centro hacia el margen, traspasarlo, no poder volver, perderse. El relato pone hábilmente en relación el interior y la interioridad de la narradora quien va en busca de esa otredad que a su vez es 
familiar, una filiación oculta o desplazada por la lejanía. En este desplazamiento, Natalia (la bruja) representa para la narradora un reflejo oscuro y tentador de lo que ella podría haber sido. Ir a la región es ir a encontrarse con una versión del yo liberada de las constricciones de la vida burguesa que se arrastran hasta allí como una carga encarnada en el personaje de Juan Martín. Si el gótico regional viene a problematizar la unidad monolítica de la nación al reivindicar una diferencia, "otro rostro", otra identidad posible de lo que era pensado como lo mismo (lo familiar), la versión de Enríquez opera, al mismo tiempo, en la dirección inversa: reintegrando lo regional en la nación ya que aunque las formas góticas se anclen en las tradiciones y leyendas locales (la bruja y el relato de fantasmas) adquieren sentido en un entramado mayor que las liga a fenómenos que deben entenderse a una escala nacional, o incluso transnacional (la caza de brujas y el terror de Estado). En este sentido, lo regional recupera ese sentido de parte subordinada a una entidad política mayor (Williams, 2000, p. 280).

En el lenguaje para decir lo regional que despliega el texto también se advierte esta tensión entre lo que se revela y lo que se oculta en los términos que se utilizan para describir el entorno y el paisaje. Esto se observa en el inicio del relato, en la preferencia de la narradora por un modo de nombrar a ciertos insectos:

No me gusta el nombre chicharra: ojalá mantuvieran siempre el nombre cícadas, que se usa sólo cuando están en etapa ninfal. Si se llamaran cícadas, su ruido de verano me recordaría las flores violetas de los jacarandás en la costanera del Paraná o las mansiones de piedra blanca con sus escalinatas y sus sauces. Pero así, como chicharras, me recuerdan el calor, la carne podrida, los cortes de electricidad, a los borrachos que miran con ojos ensangrentados desde los bancos de la plaza (2016, p.64).

Uno de los términos ("cícadas") remite a un paisaje bello y armónico que funciona como artificio que encubre la falta, la vida precarizada, la violencia; el otro ("chicharras"), revela una realidad sin filtros, en crudo. En la elección del término de resonancia literaria, el relato exhibe (a pesar de la preferencia de la narradora) cómo desde su mera descripción el paisaje en tanto artefacto cultural puede ser cómplice y encubridor de restos, violencias, inequidades que subyacen a lo pintoresco. La opción por la palabra 
que vela quizás sea un modo de anticipar el lugar de la narradora en el desenlace del relato.

\section{Postquiroguiana}

Los espacios en los que se sitúan las ficciones que reciben el atributo de "regional" o "regionalista" dependen, como señala Williams, de la distinción y tensión entre metropolitano-provinciano. Sin la lejanía y una supuesta "inferioridad" cultural respecto del centro dominante que representa la ciudad no hay posibilidad de construcción de un sentido alternativo ni del contramovimiento indicado en los usos modernos del regionalismo (2000). El relato “El lobisón” de Quiroga, publicado en Caras y Caretas en 1906, exhibe condensados la oposición entre campo-ciudad, el miedo y la adaptación y uso local de las leyendas populares. El cuento tiene un marco en el cual un grupo de personas reunidas en el patio de una estancia protagonizan una lucha entre unos perros y un animal extraño cuando uno de los hombres, Vivas, dispara y da muerte a este último. Vivas, entonces, para explicar su reacción cuenta a los presentes una historia. Ahí se inicia el relato enmarcado que constituye el centro del relato. El hombre de la ciudad cuenta que durante una temporada en la que estuvo como "patrón" en una estancia uruguaya le contaron que un peón, Ilamado Gabino, era lobisón. Este personaje aceptaba todo tipo de bromas sobre su supuesta condición. Gabino invita a Vivas a su casamiento y durante la noche de bodas, se escucha un alarido terrible que proviene de la habitación. Al llegar allí encuentran un chancho enorme junto a la novia desmayada que huye perseguido por los perros. El chancho desaparece y Gabino también. Al final, de vuelta en el marco del relato, Vivas, el hombre de la ciudad, confiesa que esa historia lo turbó y deja sugiere que el animal al que le disparó esa noche podría ser el mismo de su relato. Además de la tensión entre la cosmovisión urbana representada por Vivas (el patrón) y la de los peones del campo el relato ejemplifica muy bien el modo en que la creencia local adapta el tipo de criatura implicada en la metamorfosis a las características de la fauna local: si en la región uruguaya donde se sitúa el relato no hay lobos, el lobisón se transformará en un animal salvaje observable en la región, en este caso, el chancho. Si el relato de Quiroga narra el modo en que un sistema de creencias urbano finalmente se desmorona y Vivas termina afectado por las leyendas que habían sido objeto de burla para él, el de Enríquez presenta una mirada urbana distribuida en dos personajes cuya diferencia se

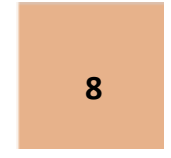

Cuadernos del CILHA n $34-2021$

ISSN 1515-6125 | EISSN 1852-9615

CC BY-NC 2.5 AR

http://revistas.uncu.edu.ar/ojs/index.php/cilha/ 
hace patente en el modo en cada uno considera al personaje de Natalia: mientras que la narradora se muestra fascinada por su prima; su marido, con aires de una supuesta superioridad porteña frente a todo lo vinculado a lo provinciano y al interior, desprecia el saber alternativo y popular que ella representa: "Tu prima es una ignorante, me dijo Juan Martín" (Enríquez, 2006, p.65). Una de las formas de leer el desenlace del relato de Enríquez ${ }^{2}$ no significa el pasaje de la incredulidad a la creencia, sino el cumplimiento siniestro del deseo que implica, a su vez, el castigo sobre quien desde una mirada urbana menosprecia los saberes y creencias de la región.

Es significativa la operación de Enríquez de abrevar en la concepción quiroguiana del espacio, no por una mera preferencia geográfica, sino porque este autor hace de la inhospitalidad del lugar "la condición de toda narración" (Andermann, 2000, p. 153). La naturaleza en la narrativa de Quiroga se conoce sólo cuando se la busca más allá de "toda voluntad de asimilación". Es decir que su otredad es solo verificable (y representable) cuando los esfuerzos civilizados de exploración y conquista, pero también de construcción de sentido, fracasan. La hostilidad espacial como condición constitutiva que se actualiza en la narración de Enríquez puede observarse ya en algunos relatos de Quiroga como "La insolación" y "La miel silvestre" sobre los cuales me quiero detener para puntualizar cuestiones que luego reaparecen trasformadas en el relato de la autora. Ya Eljaiek-Rodríguez hace un análisis de "La insolación" publicado en 1908 y recopilado en Cuentos de amor, de locura y de muerte (1917) en el que encuadra este relato como un ejemplo de tropicalización del gótico en el que la condición extrema del ambiente es la que produce el horror y la muerte $(2017$, p. 62). El narrador de este cuento de Quiroga adopta la perspectiva de unos perros en el monte chaqueño (estamos fuera de la Mesopotomia, pero no de un ambiente asfixiante y terrible en el que el sol mata). El cuento narra el modo en que estos animales atestiguan la aparición de una figura extraña que asume la forma de su dueño Mr. Jones. Mientras este personaje trabaja bajo un sol ardiente los perros observan la aparición de ese doble que encarna la muerte que va a su encuentro. El relato se sostiene en dos planos que

${ }^{2}$ El relato puede leerse de dos maneras. En una, Juan Martín decidió abandonar súbitamente el hotel por la noche sin avisar a nadie; en la otra, Natalia cumple con el deseo de su prima de deshacerse de su marido y lo hace desaparecer con sus poderes. El título "Tela de araña" abona la segunda lectura aquí enunciada.

Cuadernos del CILHA n $34-2021$ 
se articulan y convergen: en uno la explicación de lo que produce la muerte de Mr. Jones es la exposición al sol tremendo, en otra es la convergencia con esa figura especular. Es interesante esta idea de que la muerte se manifiesta como aquel que va a morir como si careciera de forma propia ${ }^{3}$. Más allá del trabajo que hace allí Quiroga con las creencias locales (la de la capacidad de los animales de percibir la muerte) es significativo cómo este relato va construyendo un espacio de límites e ilimitado al mismo tiempo. Leemos que el horizonte, como señala Margo Glantz (1976), queda confundido con el sol, pero simultáneamente se utiliza el término "linde" no sólo para delinear el territorio, sino para marcar el traspaso hacia una zona de no retorno. Esta descripción del ambiente tiene ecos que reverberan en el relato de Enríquez. Escribe Quiroga: "El aire faltaba, con angustia cardíaca que no permitía concluir la respiración" (1996, p.62). Luego: “Desde hacía rato le golpeaba en los oídos el latido de las carótidas. Sentíase en el aire, como si de dentro de la cabeza le empujaran violentamente el cráneo hacia arriba" (p.62). En "La miel silvestre" (1917) del escritor uruguayo se narra la confrontación entre el hombre de la ciudad (el contador Benincasa) y la naturaleza hostil de la selva. Su "fulminante deseo" de vida intensa lo lleva al monte armado con un machete. En su excursión encuentra en un hueco de un tronco unos panales de miel que consume ávidamente y le producen una intoxicación que lo deja paralizado. En ese momento un "precipitado río de hormigas negras" (Quiroga, 1996, p.126) (la corrección) trepa por su cuerpo y lo devora. Las "pesadillas tropicales" de Benincasa antes de su excursión fatal tienen, sin duda, continuidad en el relato de Enríquez. La construcción del ambiente es clave para la armazón textual y porta una resonancia quiroguiana que es clara ya desde las primeras líneas del relato:

Es más difícil respirar en el norte húmedo, ahí tan cerca de Brasil y Paraguay, con el río feroz custodiado por mosquitos y el cielo que pasa en minutos de celeste límpido a negro tormenta. La dificultad se empieza a sentir enseguida, ni bien se llega, como si un abrazo brutal encorsetara las costillas (2016, p.64).

\footnotetext{
${ }^{3}$ La idea de que lo que viene de más allá necesita del cuerpo de otro para manifestarse tiene resonancias en
un cuento de Mariana Enríquez titulado "Cuando hablábamos con los muertos" en el que un grupo de

${ }^{3}$ La idea de que lo que viene de más allá necesita del cuerpo de otro para manifestarse tiene resonancias en
un cuento de Mariana Enríquez titulado "Cuando hablábamos con los muertos" en el que un grupo de adolescentes en los años 90 se reúnen para comunicarse con espíritus a partir de una tabla ouija.
}

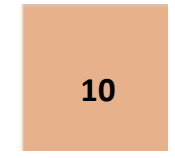

Cuadernos del CILHA n $34-2021$

ISSN 1515-6125 | EISSN 1852-9615

CC BY-NC 2.5 AR

http://revistas.uncu.edu.ar/ojs/index.php/cilha/ 
Es interesante pensar cómo este espacio inhóspito no se construye tanto como imagen visual, sino como experiencia envolvente de ahogo en la que la narradora queda inmersa. El inicio del relato marca el comienzo de asfixia que es correlativa a la que le produce su matrimonio (la elección del verbo encorsetar alimenta esta lectura). El relato narra el desplazamiento con el fin de trocar una asfixia por otra: la metafórica por la literal. El viaje hacia la región es la búsqueda de lo familiar, pero también de un cambio respecto a Juan Martín: "Decidí llevarlo a conocer a los tíos para ver si otros ojos conseguían transformarlo" (Enríquez, 2016, p.64). La formulación es curiosa: no se busca una transformación de la propia mirada para que cambie su consideración sobre su marido, ni tampoco que se modifique la visión que él sobre las cosas: sino la búsqueda de una mirada con el poder transformar a un sujeto. Sin embargo, lo que el relato nos muestra, en realidad, es la mutación de la misma narradora. Este cambio se manifiesta en un creciente y explícito deseo de que su marido muera que finalmente converge en el final con una aceptación de su posible desaparición. Lo perturbador de "Tela de araña" radica en su exhibición del modo en que una mujer hostigada y aburrida en su relación matrimonial se vuelve alguien que bajo el influjo de una selva impregnada de un pasado reciente de horror, es capaz de desear y aceptar la desaparición de otro.

No debe dejar de mencionarse que este espacio que construye Enríquez está atravesado por una temporalidad muy diferente a la que delineaba Quiroga en sus relatos. Si los textos del uruguayo como los que integran Los desterrados (1926) nos instalan en una frontera que representa un "espacio-tiempo postutópico donde todo ya pasó" (Andermann, 2000, p.159), el escenario del derrumbe de los sueños del pionerismo, en el relato de Enríquez estamos ante otro tipo de experiencia de posterioridad: la de lo postdictatorial ${ }^{4}$ que así como la quiroguiana también está poblada de seres residuales: espectros.

La otra línea que se suma y converge con la tradición del trabajo literario sobre el ambiente es la de la psicogeografía. El interés de Enríquez por la tradición de la

\footnotetext{
${ }^{4}$ Un "post" que no lo es tanto en la medida en que el cruce de la frontera hacia Paraguay vuelve presente la experiencia dictatorial. El pasaje hacia el país vecino tiene la función en el texto de hacer modular en presente lo que luego va a aparecer en los relatos de fantasmas como un retorno del pasado reciente.
}

Cuadernos del CILHA n 34 - 2021

11

ISSN 1515-6125 | EISSN 1852-9615

CC BY-NC 2.5 AR

http://revistas.uncu.edu.ar/ojs/index.php/cilha/ 
psicogeografía y en particular por sus manifestaciones contemporáneas en escritores como lain Sinclair y Peter Ackroyd se hace visible en sus reseñas, notas y entrevistas. En una reseña de un libro de Sinclair explica: "Los psicogeógrafos buscan el genius loci, el imperativo territorial que mantiene habitantes y actividades dentro del mismo y escaso perímetro: el espacio es más poderoso que el tiempo, las fuerzas topográficas trascienden los deseos humanos" (2005, p.1).

La psicogeografía, explica Merlin Coverley (2018), designa tanto un movimiento literario, un conjunto de prácticas de vanguardia, como una intervención política. Si bien este término se resiste a una definición debido a constantes reversiones y actualizaciones, su cruce entre geografía y psicología permanece desde la formulación que hizo Guy Debord en la que apuntaba a los efectos del entorno geográfico, particularmente el espacio urbano, sobre las emociones y comportamientos de los individuos. La psicogeografía postula, explica Enríquez tomando como ejemplo la propuesta de Sinclair en White Chapell, Scarlet Tracings, que el barrio de Londres donde mató Jack el Destripador, emanaba la violencia que se encarnó en ese asesino de mujeres: "un monstruo de la imaginación del lugar". Tener en cuenta el rol de la psicogeografía en la narrativa de Enríquez resignifica la presencia de enunciados como "Las cosas tardaban más en irse ahí, en el litoral” (2016, p.78). La psicogeografía suele vincularse con el gótico por el modo en que esa búsqueda del sentido o espíritu del lugar deriva hacia un rastreo de lo misterioso y oculto. De esta manera, se captan en el presente las marcas del pasado. De ahí que su labor conduzca generalmente mucho más a una forma de historia que a una investigación propiamente geográfica (Coverley, 2018). En el relato de Enríquez la unión entre el lugar y lo oscuro emerge en los relatos de aparecidos que comparten los camioneros durante la cena en el hotel en el que se ven obligados a parar. Las historias que anudan lo espectral y el terror político sugieren que el espacio queda marcado por los crímenes y el horror de forma material y eso genera una extrañeza que imanta la zona provocando las apariciones: "Me dijeron que la milicada había construido el puente y que en los cimientos usaron muertos, gente que ellos mataron, que los escondieron ahí". Crimen y espacio se funden y eso impregna el territorio: "Toda esa zona es rara, dijo, se ven luces de autos y después los coches no llegan, como si desaparecieran por algún camino, pero no hay caminos transitables, es todo selva" (2016, p.79). Para el relato esta emergencia de lo oculto del lugar no tiene

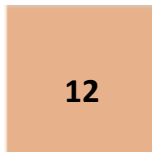

Cuadernos del CILHA n $34-2021$

ISSN 1515-6125 | EISSN 1852-9615

CC BY-NC 2.5 AR

http://revistas.uncu.edu.ar/ojs/index.php/cilha/ 
otro fin que el de sugerir una determinación fundamental del escenario sobre la narradora y su relación con Juan Martín.

\section{El relato de fantasmas}

Si bien el trabajo con la psicogeografía propone una articulación entre espacio, subjetividad y memoria que renueva la inserción de lo regional en lo literario, el uso que hace Enríquez del paisaje y entorno del litoral introduce una reflexión sobre el desfasaje temporal entre un tiempo no-humano y el humano. Mientras que "el cielo que pasa en minutos de celeste límpido a negro tormenta", al mismo tiempo "todo es más lento" (2006, p.64). Este desfasaje de dos temporalidades diferentes es lo que coagula en el "relato de fantasmas". Es decir que la selva no se vuelve material para el gótico por su "antigüedad" o preexistencia, sino por su capacidad para visibilizar bajo la forma del relato espectral la desaparición en el cruce entre lo humano (el puente, el tránsito, la modernidad) y lo no-humano (la naturaleza). Es significativo que la selva y los pueblos selváticos se constituyan en cronotopo del gótico ya que reemplazan una espacialización cerrada sobre sí misma como la del castillo, casa o mansión con una zona abierta a la circulación, a lo social. Esto se vuelve relevante en tanto la catástrofe de sentido que entraña la figura del desaparecido (Gatti, 2008) provoca una suspensión indefinida del trabajo de duelo que debe funcionar como una intermediación con la memoria cultural, de manera que obstruye la posibilidad de que lo individual se vincule a los rituales y narrativas colectivas. El relato de fantasmas ligado a la desaparición que se instala como leyenda local viene, entonces, a operar sobre la ausencia del lugar del duelo a partir de una apertura sobre lo social para reponer una conexión con lo colectivo que opera en términos de circulación en dos sentidos diferentes: la del tránsito y la de la transmisión oral. Mientras que Quiroga, como señala Andermann, narraba "los infiernos de la frontera posutópica" a partir de la vida de los desterrados que atestiguan "el fracaso de medio siglo de construir en los confines de una nación" (2000, p.160), Enríquez se instala en una frontera en donde la labor del Estado con sus puentes y caminos que integran el territorio se superpone con el terror de la desaparición. En lugar de poner en escena el destierro o la extraterritorialidad respecto a los proyectos de la modernidad como en la narrativa de Quiroga, esta superposición, que lo fantasmal viene a remover, exhibe la realización plena de un ideal moderno de racionalización, orden y purificación. Como postula Gatti, una modernidad obsesionada 
con la perfección, que tiene como fin crear una sociedad y un individuo moderno, es la misma que crea el instrumento que produce la desaparición forzada. La aparición en el ensamble entre obra pública y entorno selvático tiene así una función anti-moderna y contra-estatal: la reafirmación de una alianza de lo natural y lo sobrenatural que actúa como repetición y persistencia dando lugar a una huella de lo que la modernidad y el Estado pretendieron borrar. De ahí que las apariciones se dirijan hacia el espesor del monte, hacia donde es "todo selva" y "no hay caminos transitables". Lo interesante aquí es que Enríquez decide incorporar a su ficción situada a fines de los ochenta un relato local que proviene, más bien, del momento contemporáneo a la publicación de sus relatos: aún se pueden encontrar en la web las noticias en los diarios online sobre "la maldición" del puente que cruza el arroyo Yazá en Campo Viera ${ }^{5}$. La intervención sobre la temporalidad que realiza la autora implica situar el relato en un momento donde la circulación de discursos sobre la última dictadura argentina y los hechos aterradores que motorizó no era la misma que en el presente. Estos cuentos de fantasmas narrados por camioneros se ubican en un contexto en el que adquieren la misma función que una historia que circulaba, recuerda Piglia (2014, p. 186), durante el período de la última dictadura. Alguien contaba que había visto pasar un tren de carga interminable, lleno de ataúdes. Un relato que exhibe y no explica, no cierra la significación, explica Piglia. De la misma manera opera el relato de fantasmas en el texto de Enríquez, disputa y transgrede la difusión de información que determina quien concentra la narración pública: el Estado (Piglia, 2016). Respecto a la mujer fantasma en la ruta se hace evidente además la reversión de un motivo que representa una manifestación específica y local de un tópico global que atraviesa diferentes culturas.

\footnotetext{
${ }^{5}$ Recojo aquí algunos enlaces a notas en los diarios que permiten ver la repercusión que tuvo en los medios esta leyenda local: https://www.diariopopular.com.ar/ven-fantasmas-un-puente-maldito-n143426/, https://misionesonline.net/2017/03/17/misterio-del-puente-arroyo-yaza-se-reaviva-la-leyenda-losfantasmas/ , https://www.primeraedicion.com.ar/nota/263611/las-misteriosas-apariciones-sobre-unpuente-de-la-ruta-14/
} 


\section{La bruja mesopotámica}

Por supuesto que la narración de Enríquez no hace recaer toda su intensidad en la gravitación del escenario, sino también en el personaje de Natalia. En su reseña de la película The Witch de Robert Eggers, Enríquez (2016) cita las declaraciones del director en las que manifiesta su propósito de encontrar el camino estético para hacer de la bruja una figura vigente y poderosa. Eggers señala que para lograr ese objetivo fue central la meticulosidad. Enríquez, sin dudas, comparte esta búsqueda en su narrativa y particularmente en este relato. El cruce entre lo universal y lo local se hace evidente también en la construcción de este personaje: por un lado, sus visiones, su atractivo y su lugar desprendido de lo doméstico, por otro, su enlace con las tradiciones y leyendas de su zona que la vuelve actualización local de las figuras de la curandera y la adivina ${ }^{6}$. Esta figura adquiere sentido en términos sociales y de género dentro del triángulo de personajes que arma el relato. Natalia representa todo aquello que seduce a la narradora y que Juan Martín rechaza y teme. Es una mujer atractiva y libre que representa un poder y un saber alternativo: "él la despreciaba porque Natalia tiraba las cartas, sabía de remedios caseros y, sobre todo, se comunicaba con espíritus." (2016, p.65). No es casual entonces que quede sugerido que detrás de la desaparición de Juan Martín en el final se encuentre la tela de araña desplegada por Natalia ya que, justamente, es ella quien se opone al lazo patriarcal y burgués que "encorseta" a la narradora y que Juan Martín representa. La relevancia de esta figura de hechicera local se hace evidente aquí al tener en cuenta una investigación de la historiadora Judith Farberman que se titula Magia, brujería y cultura popular (2012). Enríquez reseña con minuciosidad este estudio que investiga la brujería en tres momentos de la historia de Santiago del Estero: el siglo XVII, a principios del siglo XX, cuando se publica El país de la selva, de Ricardo Rojas, y se realiza la Encuesta Nacional de Folklore, y por último, las décadas de 1930 y 1940 cuando Orestes Di Lullio y Bernardo Canal Feijoó realizan sus

\footnotetext{
${ }^{6}$ Los otros dos relatos que incorporan el tópico de las brujas o la brujería lo hacen de formas muy diferentes. En "El chico sucio" la religiosidad popular y la hechicería se ubican en la ciudad, más precisamente en el barrio de Constitución vinculadas a la marginalidad y al crimen y a rituales sangrientos. En "Las cosas que perdimos en el fuego" se toma el tópico de la mujer a la que se prende fuego en la hoguera, para conectarlo con la violencia de género en el presente y con una reapropiación de esa brutalidad por parte de las mismas víctimas.
} 
aportes a las pesquisas folklóricas de la región. Hay dos razones centrales que hacen que Farberman se concentre en Santiago del Estero. En primer lugar, porque los efectos de su cultura emigratoria permitieron que sus creencias populares se extendieran por el país, y en segundo lugar, y esto es algo que la historia aborda especialmente, porque en el territorio santiagueño se registran durante el siglo XVIII una serie de procesos judiciales contra brujas y hechiceras que fueron impulsados por la comunidad en general. La investigación de Farberman (2012) es relevante porque hace foco en el modo en que ha variado históricamente el lugar que ocupan las creencias ligadas a la hechicería en las distintas visiones del mundo y esto es algo, sin dudas, clave en un relato que reivindica su poder y recupera el terror reverencial hacia estas prácticas. La tensión entre Juan Martín y Natalia que pasa por el menosprecio de la mirada del hombre de la ciudad sobre las creencias populares del interior también involucra la historia de la figura de la hechicera ya que la misma estuvo durante mucho tiempo vinculada a sectores que no tenían otros recursos que los de la magia para alcanzar sus objetivos y compensar las penurias relativas a su posición de subalternidad. No sería demasiado arriesgado aventurarse a pensar que Enríquez está abrevando en estos modelos de hechiceras indias juzgadas en el siglo XVIII, revisitados por Farberman, para darle forma a la función y sentido del personaje altivo y seductor de Natalia. Por ejemplo, la investigadora recupera el caso de Juana quien confesó haberse vengado mágicamente de su marido quien la "martirizaba y maltrataba". Juana cuenta entonces cómo "siguiendo los consejos de su amiga "La Riojana", le había servido a su esposo un brebaje de agua tibia y estiércol de gallina, so pretexto de que así "echaría la póstuma"” (Farberman, 2012, p.35). La alianza táctica y mágica entre mujeres para eliminar al marido de una de ellas tiene ecos en el relato de Enríquez quien recupera para la hechicería una peligrosidad que había mantenido hasta los inicios del siglo XX cuando los discursos de la criminología positivista la ubicaban junto con todas las formas de religiosidades populares en las fronteras de delito ${ }^{7}$ (Mailhe, 2017).

\footnotetext{
${ }^{7}$ Puede leerse acá cómo el relato plantea una salida a la tradición del Marital Gothic, que identifica Ordiz, a la hora de analizar este relato (2019, p. 274). En el gótico marital se advierte el rol que cumple un esposo opresivo que plantea al principio algún tipo una liberación para la heroína pero establece luego un nuevo encierro patriarcal.
} 
Debe señalarse que este sentido de la brujería atravesado por los conflictos sociales no se restringe a lo nacional ni a lo latinoamericano, sino que ha sido estudiado también de este modo en los juicios europeos: Carlo Ginzburg afirma que las prácticas de hechicería han sido "un arma de defensa y de ataque en las disputas sociales" (2013, p.28.). Los ritos de brujería que constituyen un agenciamiento práctico del saber de los oprimidos, de esclavos y víctimas del orden normativo y que han suscitado procesos y persecuciones deben considerarse en relación con el orden del Estado Moderno (Foucault, 1996, p.29). La figura de la bruja además remite a la encarnación de una subjetividad femenina que ha resistido a los embates del sistema capitalista y debe leerse en la misma serie que la esposada desobediente, la mujer que se anima a vivir sola, la que envenena la comida del amo e inspira la rebelión de los esclavos (Federici, 2004). En Calibán y la bruja (2004), Silvia Federici explica el estrecho vínculo entre "la caza de brujas" a comienzos de la era moderna y el surgimiento y desarrollo del capitalismo que se produce al mismo tiempo en que se desata esta guerra contra las mujeres. La autora explica y repone los planteos que han advertido sobre el modo en que la persecución y ejecución de las mujeres sirvió para destruir el control de las mujeres sobre su función reproductiva. La conexión que clarifica Federici entre este fenómeno y la división sexual del trabajo que recluye a las mujeres al trabajo reproductivo hace que sea significativo que sea justamente la figura de una bruja la que desate ese nudo opresivo que representa para la narradora su matrimonio. Si bien la tela de araña parece remitir a un secreto subyacente a la superficie textual que tiende Natalia y se manifiesta finalmente en la desaparición de Juan Martín también puede considerarse como la red termina por alcanzar a la narradora quien hacia el final tiene una pesadilla de "una vieja que corría envuelta en llamas, desnuda, por una casa que se desmoronaba" (2016, p.80). Sueño que nos envía al relato misterioso de la casa incendiada que hace Natalia en dos oportunidades y que puede leerse como una interiorización de la visión de la bruja. Una interiorización que, además, es doble ya que opera como incorporación del relato dentro del propio sueño, pero que también implica una mirada hacia el interior de la casa que repone y completa aquello que no alcanza la visión de Natalia. El triángulo que constituyen los personajes queda cruzado así por otro, constituido por formas narrativas: la pesadilla, la visión, y el relato de fantasmas que se presentan, a su vez, como narraciones abiertas, que exhiben sin explicar. 


\section{Un ñandutí globalgótico}

Por último, es necesario prestar atención a un elemento vinculado al personaje de Natalia que no puede ser soslayado no sólo por su remisión en el título del cuento, sino por condensar este entramado entre lo local y lo foráneo: el mantel de ñandutí, que este personaje se destacaba por elegir, con encajes "tradicionales de Paraguay que las mujeres tejen en bastidores, telarañas de hilo delicadas y coloridas" (Enríquez, 2016, p.66). El ñandutí, de la misma manera que el gótico, fue importado y enriquecido con variantes locales. Dado que su confección constituye un proceso similar al del tejido de una especie particular de araña este encaje ha recibido un nombre que en guaraní significa "tejido de araña". El ñandutí crece y muta transplantado en la selva sudamericana. Este elemento (central a la trama en tanto motiva el viaje a Asunción) enriquece la figura de Natalia que puede pensarse además como mujer-araña, lo que implica sumar, entre muchos otros, el enlace con el mito de Aracné. En la serie literaria de hábiles tejedoras no puede dejarse afuera a la misma Enríquez cuyo relato imbrica en una red sólida y sin fisuras, la tradición del regionalismo gótico, la reescritura quiroguiana, los recursos del relato de terror, y las creencias locales de manera tal que construye su propio ñandutí globalgótico.

En el contexto de estudios sobre el gótico latinoamericano este trabajo sobre "Tela de araña" de Mariana Enríquez ha tenido como objetivo integrarse, por un lado, a planteos como los de la "tropicalización del gótico" de Eljaiek-Rodríguez (2017) que apuntan a la utilización de motivos y formas narrativas góticas por parte de los escritores latinoamericanos por medio de una operación de transplante y desubicación en función de reescribir las relaciones políticas e históricas específicas del continente. Pero, por otro lado, hacer resonar, también, los sentidos en un entramado compuesto por las relaciones entre ciudad e interior, periferia y centro, en clave nacional. De ahí que el regionalismo gótico constituya aquí una elaboración en la que la región es un vector disparado hacia el espacio transnacional, pero también una zona que adquiere sentido en el contacto y la fricción hacia el interior del Estado-nación. A esta combinación de fuerzas centrípetas y centrífugas se le ha sumado la consideración de un diálogo con otras lecturas y tradiciones que le permiten a la autora renovar la incorporación de lo regional en el plano de lo literario como la psicogeografía.

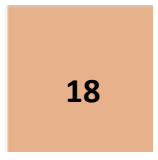


El sentido antipatriarcal que se ha explorado aquí condensado en la figura de la bruja dialoga con las reflexiones sobre el gótico femenino y feminista en los textos de Enríquez (Ordiz, 2019; Rodríguez de la Vega 2018; Gallego Cuiñas 2020) y busca subrayar cómo en ese trabajo de incorporación de un modelo que tiene una resonancia global, es posible leer también una atención a las particularidades que adquiere esa figura a la luz de los testimonios históricos sobre la hechicería y las creencias populares a nivel local. Por último, cabe agregar que el presente análisis ha demostrado la manera en que el gótico en este relato de Enríquez vehiculiza su intervención política a partir de formas narrativas como la visión, la pesadilla y el relato de fantasmas cuya potencia conjunta no radica en la mera señalización de una dimensión desprendida de lo racional, sino en su valor como mecanismos que operan a contramano de los cierres. $\mathrm{Si}$ bien los fantasmas en este cuento emergen como visibilización de la violencia, la tortura y persecución del pasado, en línea con lo que se ha teorizado acerca del gótico latinoamericano (Edwards y Vasconcelos, 2016, p.3), una diferencia puntual se apoyaría en el valor transgresor que adquiere el mismo cuento de fantasmas no por su tema o contenido, sino en tanto forma cuya circulación plantea un desafío a la concentración y control de la narración pública por parte del Estado.

\section{Referencias}

Andermann, J. (2000). Mapas de poder: una arqueología literaria del espacio argentino. Beatriz Viterbo Editora.

Botting, F., Edwards, J. (2015). Theorising globalgothic. In G. Byron (ed), Globalgothic (págs. 11-24).

Manchester University Press.

Byron, G. (ed.) (2015). “Introduction”. En Globalgothic. Manchester University Press

Casanova-Vizcaíno, S., y Ordiz, I. (Eds.). (2017). Latin American Gothic in Literature and Culture. Routledge.

Contreras, S. (2013). Realismos, cuestiones críticas. En S. Contreras (Ed.), Realismos, cuestiones críticas (págs. 5-25). Centro de Estudios de Literatura Argentina.

Coverley, M. (2018). Psychogeography. Oldcastle Books Ltd.

Deleuze, G., Guattari, F. (2002). Mil mesetas. Capitalismo y esquizofrenia. Pre-textos.

Edwards, J., Vasconcelos, S. (eds.) (2016). Tropical Gothic in Literature and Culture: The Americas. Routledge.

Eljaiek-Rodríguez, G. (2017). Selva de fantasmas: el gótico en la literatura y el cine latinoamericanos. Editorial Pontificia Universidad Javeriana. 
Enríquez, M. (2005, 6 de febrero). Excéntricos y visionarios. Radar Libros. Página 12. https://www.pagina12.com.ar/diario/suplementos/libros/10-1415-2005-02-06.html

Enríquez, M. (2011, 9 de enero). Viejas brujas. Radar Libros. Página 12.

https://www.pagina12.com.ar/diario/suplementos/libros/10-4124-2011-01-09.html

Enríquez, M. (2009). Los peligros de fumar en la cama. Emecé.

Enríquez, M. (2016). Las cosas que perdimos en el fuego. Anagrama.

Enríquez, M. (2016, 13 de marzo) Cruz diablo. Radar Libros. Página 12.

https://www.pagina12.com.ar/diario/suplementos/radar/9-11338-2016-03-13.html

Farberman, J. (2012). Magia, brujería y cultura popular: De la colonia al siglo 20. Sudamericana.

Federici, S. (2004). Calibán y la bruja: mujeres, cuerpo y acumulación originaria. Traficantes de Sueños.

Fiedler, L. (1997). Love and death in the American novel. Dalkey Archive Press.

Foucault, M. (1996). Médicos, jueces y brujos en el siglo XVII. En La vida de los hombres infames (págs. 2136). Editorial Altamira.

Gallego Cuiñas, A. (2020). El feminismo gótico de Mariana Enríquez. Latin American Literature Today, 14, 16. http://www.latinamericanliteraturetoday.org/es/2020/mayo/el-feminismo-g\%C3\%B3tico-de-marianaenr\%C3\%ADquez-de-ana-gallego-cui\%C3\%B1as

Gatti, G. (2008). El detenido-desaparecido: narrativas posibles para una catástrofe de la identidad. Ediciones Trilce.

Ginzburg, C. (2013). Brujería y piedad popular. Notas a propósito de un proceso de 1519. En Módena. Mitos, emblemas, indicios. Morfología e historia (págs. 21-46). Prometeo.

Glantz, M. (1976). Poe en Quiroga. En Á. Flores (comp.), Aproximaciones a Horacio Quiroga (págs. 93-118). Monte Ávila Editores.

Hedrick, T. (2017). The Spirits Talk to Us: Regionalism, Poverty, and Romance in Mexican American Gothic Fiction. Studies in the Novel, 49 (3), 322-340.

Heholt, R., y Hughes, W. (2018). Gothic Britain: dark places in the provinces and margins of the British Isles. University of Wales Press

Mailhe, A. (2017). Creencias y supersticiones en conflicto: visiones de la religiosidad popular en la Argentina de entre siglos. Orbis Tertius, XXII (26), e051, 1-12. https://doi.org/10.24215/18517811e051

Negroni, M. (2015) La noche tiene mil ojos. Caja Negra.

Ordiz, I. (2019). De brujas, mujeres libres y otras transgresiones: el gótico en Las cosas que perdimos en el fuego de Mariana Enríquez. En N. Ávarez Méndez, y A. Abello Verano (eds.), Realidades fracturadas.

Estéticas de lo insólito en la narrativa en lengua española (1980-2018) (págs. 263-285). Visor Books, S.L.

Piglia, R. (2014). Modos de narrar. En Antología Personal (págs. 255-267). Fondo de Cultura Económica.

Piglia, R. (2016). Las tres vanguardias: Saer, Puig, Walsh. Eterna Cadencia.

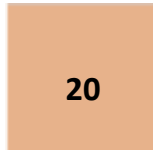

Cuadernos del CILHA n $34-2021$

ISSN 1515-6125 | EISSN 1852-9615

CC BY-NC 2.5 AR

http://revistas.uncu.edu.ar/ojs/index.php/cilha/ 
Piglia, R. (1993). Quiroga y el horror. La gallina degollada de Horacio Quiroga. En La Argentina en pedazos (págs. 1-9). Ediciones de la Urraca.

Quiroga, H. (1996). El Lobisón, La miel silvestre, La insolación. En Todos los cuentos. ALLCA XX.

Raymond, W. (2000). Palabras clave. Un vocabulario de la cultura y la sociedad. Nueva Vision.

Rodríguez de la Vega, V. (2018). Desafiando al patriarcado a través del fuego: el empoderamiento de las mujeres en Las cosas que perdimos en el fuego de Mariana Enríquez. Transmodernity: Journal of Peripheral Cultural Production of the Luso-Hispanic World, 8 (1), 144-161 https://doi.org/10.5070/T481039390 